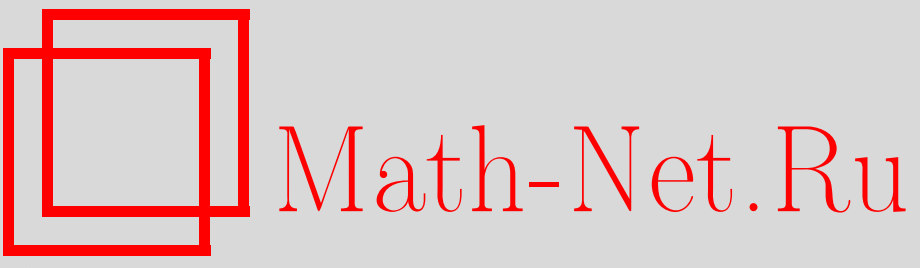

A. P. Beltúkov, S. G. Maslov, About problems of readers and the process of reading in the electronic environment, Vestn. Udmurtsk. Univ. Mat. Mekh. Komp. Nauki, 2010, Issue 4, 101-111

Use of the all-Russian mathematical portal Math-Net.Ru implies that you have read and agreed to these terms of use

http://www . mathnet.ru/eng/agreement

Download details:

IP : 34.239 .49 .27

April 26, 2023, 07:58:21 


\title{
КОМПЬЮТЕРНЫЕ НАУКИ
}

\author{
УДК 004
}

(C) А. П. Бельтюков, С. Г. Маслов

\section{О ПРОБЛЕМАХ ЧИТАТЕЛЕЙ И ПРОЦЕССЕ ЧТЕНИЯ В ЭЛЕКТРОННОЙ СРЕДЕ ${ }^{1}$}

\begin{abstract}
«Жизнь коротка, и по ту сторону ее никого не спросят о количестве одоленных книг. И поэтому неумно и вредно тратить время на чтение, не представляющее ченности ...

Бездумное, рассеянное чтение - это то же, что прогулка по прекрасной местности с завязанными глазами.»
\end{abstract}

Герман Гессе

На основе системного анализа рассмотрены ситуации взаимодействия субъекта с системой знаний, представленных в виде цифровых книг. Проведено сравнение традиционных форм книг. Классифицированы виды чтения. Предложены основные направления развития цифровых книг и технологий чтения в контексте эволюционирующей системы знаний.

Ключевые слова: «цифровые» издания, конструктивные электронные издания, «живая» книга, фонд изданий, типы читателей, процесс чтения, типы чтения, ситемный анализ.

\section{Введение}

Миф о самой читающей стране рухнул. Качество образования резко снижается. И это совсем не удивительно. В чем причины этого и каковы решения, которые кардинальным образом способны изменить ситуацию? Почему бюрократическая машина побеждает разумный процесс? Ведь совсем недавно каждый советский человек тратил на чтение почти час ежедневно и этим процессом было охвачено свыше $90 \%$ населения. Был острый дефицит книг, люди годами искали необходимые книги. Но наступило «изобилие», появились новые формы распространения информации - чаты, «интернет-свалки», рекламные «дезинформаторы» и многое другое. Пропала культура чтения и речи, темп жизни провоцирует к действию, а не к размышлению, особенно в условиях стремления к успешности и наживе, а не к благу и гармонии. По данным сайта «RUMETPИKA», тенденция потери читателей прогрессирует, и сегодня уже среди россиян $35 \%$ вообще не читают или читают очень редко, $43 \%$ - от случая к случаю и только $22 \%$ читают постоянно и ежедневно. И в этих условиях мы собираемся опередить и удивить весь мир прорывными и инновационными технологиями!

Кроме того, глядя на неуклюжие эклектические попытки наших «хронофагов» приспособить новые информационные технологии к старомодным московским требованиям образовательных стандартов и нормативов «лицензирования-аттестации-аккредитации» учебных заведений, «приходят в голову следующие мысли» (здесь намеренно допущена типичная для наших студентов ошибка в русском языке: по всей видимости, «мысли» все же никуда не «глядели»«глядели» сами авторы).

Обеспечение студентов горами макулатуры, состоящими из бумажных томов литературы, когда «на дворе 21-й век» и можно иметь ту же литературу на «электронных» («цифровых») носителях, - явный анахронизм. Ситуация усугубляется требованием раз в 5 лет обновлять учебную литературу. Это достаточно эффективно для «бумажных» книгоиздателей, и не вызывает никакого сомнения, что их прибыль при выполнении этого требования будет оставаться на высоком уровне. «Цифровые» издания, копируя печатные, стоят столько же, сколько и «бумажные», - это финансовый «беспредел» и «дикость» рынка. Очевидно и то, что упомянутая

\footnotetext{
${ }^{1}$ Работа выполнена при финансовой поддержке РФФИ (грант 08-07-00460-а).
} 
выше «эффективность» не имеет прямого отношения к эффективности учебного или познавательного процесса: литература по отношению к требованиям обновления образует обширную шкалу, на одном конце которой находится эфемерная литература, типа «Последняя версия операционной системы Х», требующая чуть ли не ежегодного обновления, на другом конце классические учебники начала фундаментальных наук, для которых содержание основ, преподаваемых на начальных курсах, не меняется десятилетиями.

«Хотели как лучше, а получили. ..»- не «как всегда», а «хуже некуда». Фактически возникла новая ситуация в области распространения и использования знаний, требующая новых решений. Надо, наконец, определиться с теми проблемами, с которыми мы столкнулись, и найти методы их решения.

Перечислим основные цели данной статьи:

1. Предложить способ приведения основных средств накопления и формирования знаний (книга, библиотека, фонд) в форму, соответствующую уровню развития современных средств ИТ-сферы и когнитивных наук.

2. Раскрыть новые возможности в организации чтения и создании электронных (цифровых) изданий.

3. Стимулировать анализ и решение проблем формирования эффективных потоков знаний и совершенствования среды их распространения.

\section{§1. Проблемы, модели и решения}

Если мы хотим разобраться в процессе чтения, то необходимо рассматривать всю системную ситуацию, то есть понять, что такое книга, кто с ней взаимодействует, какова роль читателя, для чего осуществляется чтение, и, наконец, понять, что такое чтение, какие факторы влияют на эффективность и качество чтения? В процессе ответа на эти вопросы мы будем сталкиваться с различными препятствиями, противоречиями и проблемами, разрешение которых и будет формировать необходимый нам путь решения.

О книге и ее создании. В современной практике наиболее используемые виды книг и их основные свойства можно представить в виде таблицы (таб. 1). При анализе этой таблицы становится очевидным превосходство цифровых книг над «бумажными». Главным отличием является активный характер использования информации и знаний, когда новое знание или понимание меняет книгу, а задачи и способности конкретного читателя встраиваются в процесс использования книги. Фактически речь идет о создании динамических (или активных) интерактивных книг, содержащих выполняемые фрагменты, взаимодействующие с читателем (например, автоматически проверяемые упражнения) и отражающие индивидуальные траектории в системе знаний, в процессе чтения которых создаются новые объекты и процессы.

Таблица 1: Виды книг и их основные свойства

\begin{tabular}{|r|l|c|c|c|}
\hline \hline № & Состав и свойства & \multicolumn{2}{|c|}{ Книга } \\
\hline \hline 1. & Основа & $\begin{array}{c}\text { «печатная» } \\
\text { «бумажная» }\end{array}$ & аудио & $\begin{array}{c}\text { цифровая } \\
\text { (электронная })\end{array}$ \\
\hline 2. & Простой текст & + & - & + \\
\hline 3. & Гиперссылки & пассивные & - & + \\
\hline 4. & $\begin{array}{l}\text { Графика (схемы, изображе- } \\
\text { ния) }\end{array}$ & + & + & + \\
\hline 5. & $\begin{array}{l}\text { Звук (авторский, дикторский, } \\
\text { музыка, синтезированный) }\end{array}$ & - & + & актие \\
\hline 6. & Видео и анимация & «примитивная» & «абстрактная» & «полноценная» \\
\hline 7. & Полисенсорность & - & - & + \\
\hline 8. & Статичность & + & - & + \\
\hline
\end{tabular}




\begin{tabular}{|c|c|c|c|c|}
\hline \multicolumn{5}{|c|}{$\overline{~ П р о д о л ж е н и е ~ . . . ~}$} \\
\hline № & Состав и свойства & & Книга & \\
\hline 9. & Квазидинамичность & $\begin{array}{c}\text { развернутое } \\
\text { в пространстве } \\
\text { изображение }\end{array}$ & - & + \\
\hline 10. & Динамичность & - & + & + \\
\hline 11. & Интерактивность & - & - & + \\
\hline 12. & $\begin{array}{l}\text { Проецируемость (точка зре- } \\
\text { ния) }\end{array}$ & «ручная» & «ручная» & автоматизированная \\
\hline 13. & $\begin{array}{l}\text { Читабельность } \\
\text { и удобство чтения текста) }\end{array}$ & $\begin{array}{c}\text { + (напр., } \\
\text { разбиение текста } \\
\text { на колонки) }\end{array}$ & - & $\begin{array}{c}\text { + (напр., выдача } \\
\text { текста } \\
\text { в фиксированное } \\
\text { место) } \\
\end{array}$ \\
\hline 14. & Полиграфичность & + & - & + \\
\hline 15. & Масштабируемость & $\begin{array}{c}\text { (напр., c } \\
\text { помощью лупы })\end{array}$ & $\begin{array}{l}\text { управление } \\
\text { громкостью }\end{array}$ & + \\
\hline 16. & Кроссплатформенность & не нуждается & $\begin{array}{l}\text { в цифровом } \\
\text { виде есть }\end{array}$ & + \\
\hline 17. & Конвертируемость & сканируется & $\begin{array}{c}\text { в цифровом } \\
\text { виде есть }\end{array}$ & + \\
\hline 18. & $\begin{array}{l}\text { Конструктивность } \\
\text { (преобразование формы) }\end{array}$ & $\begin{array}{c}\text { с автономным } \\
\text { результатом }\end{array}$ & $\begin{array}{c}\text { с автономным } \\
\text { результатом }\end{array}$ & $\begin{array}{c}\text { со встроенным } \\
\text { результатом }\end{array}$ \\
\hline 19. & $\begin{array}{l}\text { Транспортируемость } \\
\text { (мобильность) }\end{array}$ & «тяжелая» & «легкая» & «легкая» \\
\hline 20. & Возможности навигации & $\begin{array}{c}\text { содержание, } \\
\text { указатели }\end{array}$ & $\begin{array}{c}\text { по времени или } \\
\text { по модулям }\end{array}$ & $\begin{array}{c}\text { тематическая, } \\
\text { целевая, } \\
\text { индивидуальная, }\end{array}$ \\
\hline 21. & Возможности поиска & $\begin{array}{c}\text { «ручной» } \\
\text { по указателям } \\
\text { или сквозным } \\
\text { просмотром }\end{array}$ & - & $\begin{array}{c}\text { автоматический } \\
\text { по запросам }\end{array}$ \\
\hline 22. & Возможности редактирования & $\begin{array}{c}\text { «неестественное», } \\
\text { пометки, } \\
\text { комментарии, } \\
\text { коррекция } \\
\end{array}$ & - & $\begin{array}{c}\text { «целевое», режимы } \\
\text { соавторства }\end{array}$ \\
\hline 23. & $\begin{array}{l}\text { Возможность исполнения «тек- } \\
\text { ста» }\end{array}$ & - & - & $\begin{array}{c}\text { встраиваемый или } \\
\text { внешний исполни- } \\
\text { мый формальный } \\
\text { код; синтез фор- } \\
\text { мальных описаний, } \\
\text { речи, } \\
\text { изображений, . . . } \\
\end{array}$ \\
\hline 24. & $\begin{array}{l}\text { Возможность преобразования } \\
\text { (семантики) }\end{array}$ & - & - & + \\
\hline 25. & $\begin{array}{l}\text { Проверка на соответствие } \\
\text { (напр., плагиата или стиля) }\end{array}$ & «ручная» & «ручная» & автоматизированная \\
\hline 26. & Әргономичность & «средняя» & «минимальная» & «максимальная» \\
\hline 27. & $\begin{array}{l}\text { Естественный и искусственный } \\
\text { компьютинг }\end{array}$ & - & - & $\begin{array}{c}\text { (напр., «самопре- } \\
\text { образование» })\end{array}$ \\
\hline 28. & Возможность сохранения & 100,1000 лет & 10 лет & 10 лет \\
\hline 29. & $\begin{array}{l}\text { Возможность адаптации к чи- } \\
\text { тателю и решаемым задачам }\end{array}$ & - & - & $\begin{array}{c}\text { анимат или сеть } \\
\text { аниматов }\end{array}$ \\
\hline
\end{tabular}

В этой ситуации все бумажные учебники разумно перевести в «цифровую» форму: сначала в аналог печатного издания (форматы PDF, DJVU, FB2, ...), а затем переработать в более совершенный вид. Для разных видов литературы следует четко определить критерии обновле- 
ния. Учебники по авторским курсам, определяемым вузом, следует также издавать в цифровом виде самим вузам.

При переходе на такую систему можно пойти на поставку учебной литературы «по подписке». Такие книги являются «живыми»: для них непрерывно выходят обновления, автоматически «инсталлируемые» «читалками» через информационные сети. Такая книга из книгипредмета превращается в книгу-услугу. Более того, подписка может означать и обратную связь с читателем, который может выдвигать свои замечания и пожелания по книге и оформлять их в самостоятельный слой. Читатель трансформируется сначала в критика, затем - в соавтора.

Книга может иметь представительства в информационных сетях, где помещаются комментарии, идет обсуждение с использованием самых современных методов информационного взаимодействия. В этом случае мы будем иметь действительно «живую книгу». В случае, который с современных позиций представляется «предельным», книга должна быть полностью распределенно-сетевой, имея минипредставительства на каждом устройстве читателя. Эти представительства могут взаимодействовать между собой, обеспечивая взаимное обогащение и развитие самих читателей.

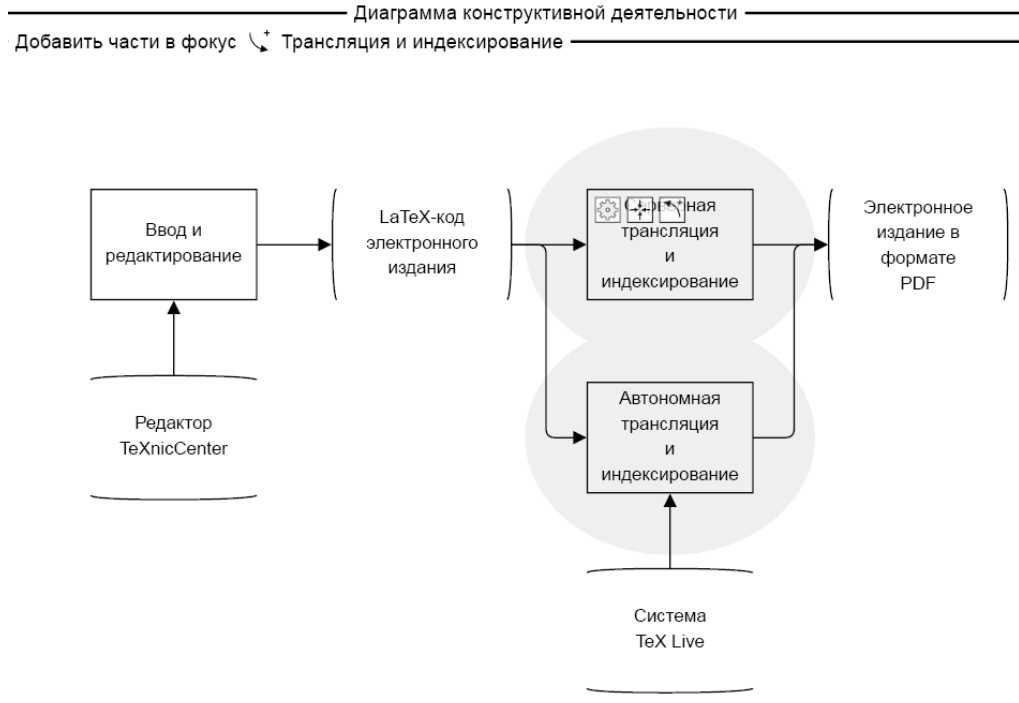

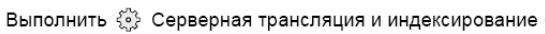

Рис. 1. Фрагмент работы с КЭИ

Естественно, при таком подходе требуется реорганизация института «прав на копирование», сейчас лишь защищающего права издателей, но не авторов и читателей. Предлагается подойти к проблеме авторских прав с другой стороны: если учебное заведение объявило о выполнении им какой-то образовательной программы, которая подразумевает использование некоторых официально рекомендованных литературных источников, то ему придется автоматически отчислять через официального «издателя» денежные средства за использование выбранной литературой в объеме, пропорциональном лицензируемому (отчетному) контингенту учащихся. Кроме того, необходимо урегулировать соответствующим образом авторские и издательско-технические отчисления (автору и издателям в соответствии с долей ответственности за качество издания). Один из вариантов такого урегулирования состоит в том, что, начиная с некоторой начальной пропорции распределения вознаграждения между автором и издателем, запускается процесс оптимизации этого соотношения. Например, достаточно изначально оставить за автором $62 \%$ прибыли от всего тиража, а оставшуюся долю - $38 \%$ определить для организации издательского дела. По идее, это должно стимулировать процесс производства нового знания. В любом случае такой механизм урегулирования, учитывающий два фактора создаваемого продукта - цену и ценность, должен быть разработан. 
Современная «цифровая» книга должна гармонично сочетать эмоциональную форму обычного изложения с системно-конструктивной формой, резко сокращающей дублирование информации и знаний. В этой связи можно рассмотреть новый класс электронных изданий - конструктивные электронные издания (или КЭИ), введенный в работах [2-4].

Под конструктивным электронным изданием понимается основная форма отчуждения продукта мыслительной деятельности сублекта (автора), предназначенная для накопления, эффективной переработки знаний и организации конструктивной деятельности на их основе, то есть электронная форма передачи опыта, знаний и умений другим суббектам читателям (см., пример, рис. 1).

Такое схемное описание допускает ряд операций динамического интерактивного взаимодействия читателя с книгой (см. рис. 2). В частности, на рисунке 1 серыми облаками выделена активизируемая часть схемы, которая допускает операции «выполнение», «фокусирование» и переход «к целому» (пример взят из презентации к работе [3]).

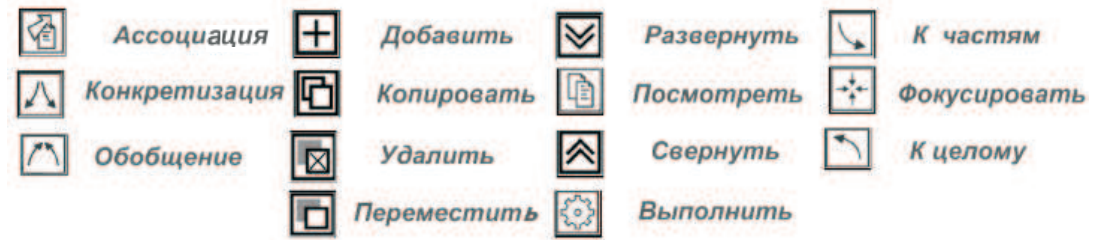

Рис. 2. Операции динамического интерактивного взаимодействия с КЭИ

\section{ТЕХНОЛОГИЯ}

- это прочесс организации обгектов и процессов и их преобразований с целъю репродукиии или создания (синтеза) нового обвекта или процесса

с заданным качеством и в рамках выделенных ресурсов.

Схемное описание может заменять текстовое описание, предоставляя читателю более удобную для него форму восприятия информации (см., например, рис. 3). Книги могут представлять собой переплетающиеся слои описаний, движение по которым осуществляется с помощью специального средства, так называемого анимата (название взято из работы [12]) или сети таких аниматов. Анимат обязан следить за развитием ситуации «чтения», моделировать и трансформировать ее для достижения цели, контролируя решаемую задачу, используемые и имеющиеся средства решения, эмоциональное состояние субъекта, возникающие у него трудности и проблемы. Кроме того, могут сохраняться индивидуальные траектории движения по слоям информации и знаний. Таким образом создается почва для развития субъекта, обеспечивается более полное, эффективное и эмоциональное представление субъекта об исследуемом или конструируемом объекте (или процессе) или о самом себе.

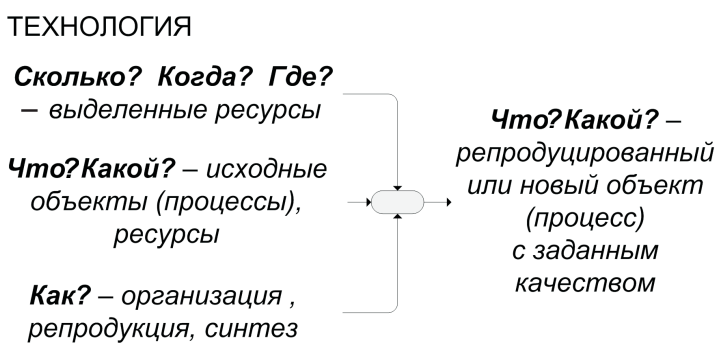

Рис. 3. Фрагмент КЭИ: «эмоциональное» и формализованное описание

В рамках данного подхода получает развитие коллективная, когнитивная и конструктивная деятельность, которая повышает достоверность накапливаемых знаний и создает возможность решения более сложных теоретических, технологических и практических задач. Здесь становятся важными механизмы определения наиболее компетентного субъекта в группе (лидера) относительно решаемой проблемы и ее декомпозиции. 
Для разработки КЭИ требуется также нетрадиционный процесс (см. рис. 4), который опирается, прежде всего, на дескриптивно-конструктивное описание, анализ и синтез, а не на некоторый «литературный» стиль. Фактически в этой книге представляется не только содержательная информация, но и параллельно создаются слои для представления анимата, то есть создается жизненная среда этой книги (см. работы [5-12]).

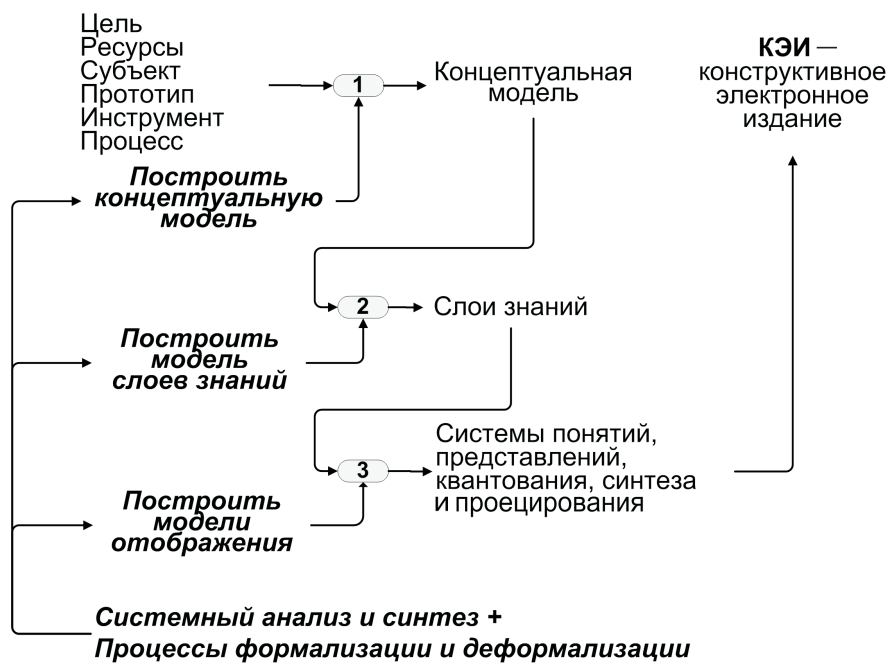

Рис. 4. Процесс построения КЭИ

Если всем учебным заведениям перейти на использование литературы в электронном виде, то при этом все учащиеся должны быть, естественно, обеспечены средствами доступа к этой литературе. Эти средства могут быть как их собственные средства, так и средства, предоставляемые учебным заведением. Речь здесь ни в коем случае не идет о предоставлении дорогостоящих персональных компьютеров, необходимых разве лишь для сверхдинамичных игртренажеров виртуальной трехмерной реальности (хотя, возможно, это и требуется для обучения летчиков и гимнастов, но это - явно не «литература», а «оборудование»). Речь идет о недорогом, но эргономичном оборудовании, годящемся на роль «читалок». К сожалению, рынок «читалок» в России практически не развит. Надо прекратить строительство библиотек в виде громадных «бумагохранилищ» и перейти к строительству «цифровых» читальных залов и библиотечных датацентров. К слову, миллион томов по 500 страниц чистого текста занимает один терабайтный «винчестер», который теперь уже помещается в кармане. Конечно, такие же тома, но с красивыми картинками и видео, займут уже небольшое помещение. Кроме того, посещение датацентра не требует физического перемещения читателя. Такой класс текстов как инструкция встраивается непосредственно в оборудование (smart-оборудование) и не требует дополнительного хранения. Обобщенная система доступа к книгам в итоге должна представлять собой фонд изданий и публикаций (см. рис.5), который предоставляет информацию как в стационарном, так и в мобильном виде, то есть там, где это необходимо, и тогда, когда это нужно $[1,5-11]$

Читатель, Рецензент, Автор, Соавтор, Издатель, ...

\begin{tabular}{|c|c|}
\hline \multirow{3}{*}{ ФОНД } & Технологчи чтения и создания изданий \\
\cline { 2 - 2 } & БИБЛИОТЕКА - печатные издания \\
\hline \hline ДАТАЦЕНТР - цифровые издания \\
\hline
\end{tabular}

Рис. 5. Фонд изданий и публикаций 
О читателях и чтении. Герман Гессе, анализируя процесс книжного чтения, выделил три типа читателей:

- наивный читатель (ведомый) по отношению к чтению - не личность;

- гений игры (следопыт), который следует своей природе, а не образованию, для которого «эстетические ценности почти совершенно пропадают и наибольшую прелесть и ценность начинают представлять только промахи и нечеткости»;

- генератор идей (мечтатель), для которого фантазия и ассоциативная способность переживают кульминацию и который читает уже совсем не то, что видит перед собой на бумаге, а плывет в потоке стимулов и идей, почерпнутых им из прочитанного.

Эти типы читателей хорошо отражают эмоциональные и когнитивные аспекты процесса чтения. Для полноты картины необходимо ввести дополнительный тип читателя, отражающий конативные, креативные и конструктивные аспекты процесса чтения:

- твореи (конструктор) - это тот, кто четко осознает границу реальности и вымысла и кто из невозможного создает возможное.

Форма, логика и содержание книги, цель чтения (или результат), а также объем знаний, которым обладает читатель, - это те факторы, которые влияют на эффективность процесса чтения. Фактически в реальном процессе чтения типы читателей, возможно, более точно соответствуют состояниям обобщенного синтетического процесса чтения и проявляются в одном и том же человеке.

Процесс чтения как творческий акт можно разделить на три основные фазы:

- конвергентная, когда результат чтения строится из систем, понятий, соответствующих цели чтения, знаниям субъекта и содержанию книги (спираль Абдеева, кибернетика);

- дивергентная, когда для получения результата необходимо формировать новую точку зрения, переходить к другим книгам, общаться с другими субъектами (спираль Гегеля, либернетика);

- разрешение противоречий (или преодоление препятствий и барьеров), то есть создание синтетического образа.

Если подходить к процессу чтения более технично, то лингвисты, например, рассматривая процесс чтения как процесс восприятия и понимания естественного текста (ЕТ), выделяют следующие способы [17]:

- пофразное, буквальное, поэлементное чтение и понимание ЕТ;

- подробное понимание, но в масштабе текста и с отождествлением сущностей, упоминаемых в разных фразах;

- беглое чтение, выбирающее из ЕТ нужные терминологические элементы;

- чтение «крупным планом», выхватывающее из ЕТ необходимые сюжеты.

Чтение гуманитарных текстов отличается от чтения естественно-научных и научно-технических. Последние имеют более сложные статические и динамические взаимосвязи, более формализованные, а не конкретные представления о действительности, более непредсказуемые результаты. Кроме того, естественно-научные и научно-технические тексты сейчас, фактически, превращаются в полисенсорные тексты, над которыми возможны различные преобразования 


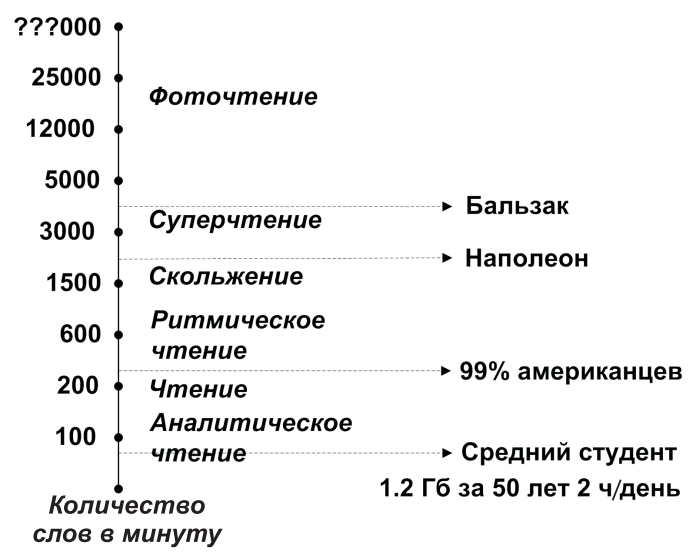

Рис. 6. Скорость чтения

(внешний компьютинг), и часто читатель постепенно превращается в процессе чтения в соавтора или сотворца. Очень часто эффективность чтения связывают со скоростью чтения, обобщенное представление о котором (из работ [13-16]) отражено на рисунке 6.

Безусловно, скорость и объемы чтения, проявляемые средним студентом, явно недостаточны. Однако приоритет в чтении научно-технической и научно-естественной литературы смещен в сторону: от разнообразия и полноты переживаемых чувств к результативности построения абстрактных образов и процессов их материализации. Одной скорости и навигации явно мало, необходимы разнообразные преобразования получаемой информации, установление аналогий, оперирование идеальными и конкретными образами, выход за границы возможного. Все это приводит к разнообразным точкам зрения на формирование процессов чтения.

В частности, чтение молитв можно рассматривать как конативное чтение. Построение морфологического, функционального, атрибутивного, либернетического и генетического описания систем в процессе чтения можно рассматривать как когнитивное чтение (см. рис.7, более подробно - [6-11]).

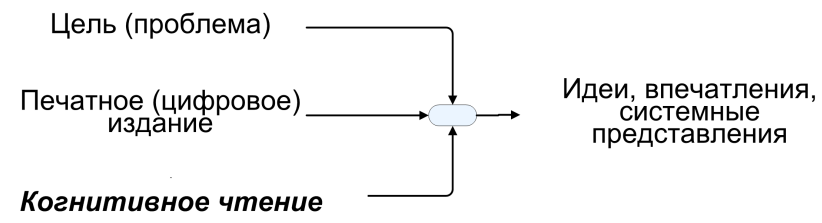

Рис. 7. Когнитивное чтение

Когда процесс чтения сопровождается построением нового или восстановлением, репродуцированием ранее существовавшего объекта (или процесса), то можно говорить о конструктивном чтении. А если вы не хотите потерять или улучшить, например, зрение, то можно говорить о корректирующем чтении (см. рис. 8, 9, более подробно - [6-11]).

Неудачи конструктивного чтения могут, например, означать следующее:

А - объект вообще не создан или все ресурсы израсходованы;

В - объект создан, но не того качества;

C - создан объект требуемого качества, но неэффективным образом;

D - создан объект требуемого качества, но система ценностей и потребностей субъекта изменилась.

Следует отметить, что все перечисленные типы чтения могут эффективно реализовываться только на «живых» книгах, которые реализуют динамическое интерактивное взаимодействие 


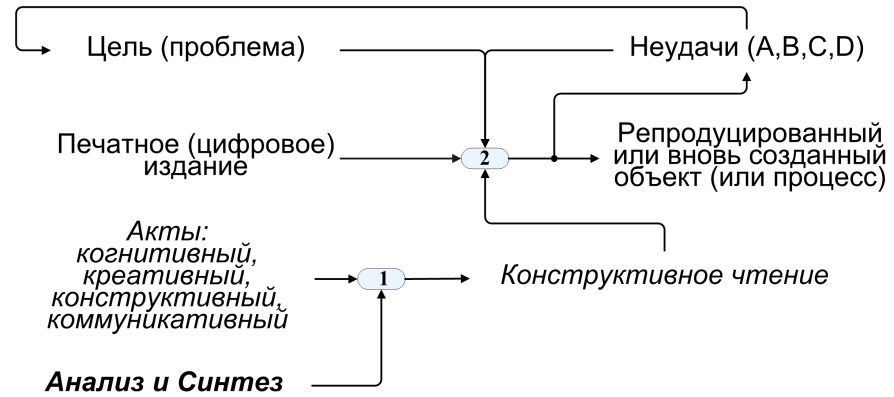

Рис. 8. Конструктивное чтение

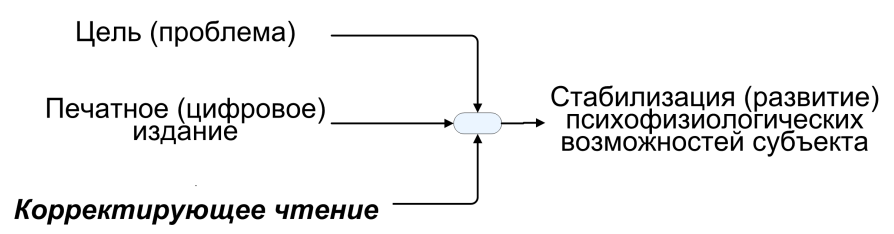

Рис. 9. Корректирующее чтение

человека с системой знаний и могут привлекать в процесс чтения различные средства естественного и искусственного компьютинга как катализатора, интеллектуального усилителя или организатора процесса чтения (в широком смысле этого слова). Наиболее подходящей для этого является «цифровая» форма, погружающая в различные среды компьютинга и реализующая или поддерживающая индивидуальную и коллективную дескриптивно-конструктивную деятельность

\section{§ 2. Результаты}

Проведен системный анализ проблем форм отчуждения знаний и их распространения. Предложена общая организация ситуации, связанной с чтением, читателем и построением книг, приводящая к эффективному использованию эволюционирующей системы знаний.

\section{§ 3. Заключение}

Эпоха примитивной компиляции, мультипликации и гиперссылочности уже заканчивается, на смену им приходит построение книг и систем знаний на основе использования и поиска новых фундаментальных принципов, в частности, в ИТ-сфере [18], естественного и искусственного компьютинга, симбиоза человека со средой знаний (или ИТ-системой), непрерывного и опережающего синтеза, когда «мнимое» разнообразие информации и знаний должно вытесниться действительно достоверным знанием. Основная цель на современном этапе состоит в том, чтобы обучаемый или исследователь, получая «Живую книгу», мог формировать свою личную «Книгу жизни», позволяющему ему достигать творческих вершин, эффективности и гармоничности жизни. Старая книга остается и как раритет является бесценным артефактом уходящей культурной эпохи.

Современное чтение - это глубокое понимание, реконструкция или создание нового, это живой процесс движения информации и знаний, требующий создания новых форм и процессов. Это процесс действительного применения и освоения новых знаний, а не его складирование и бесконечный поиск. Это активное, а не пассивное отношение субъекта к получаемой информации и знаниям.

\section{СПИСОК ЛИТЕРАТУРЫ}

1. Maslov S. G., Dunaev D. A., Ilinykh M.S. Electronic Publishing Fund for engineering educating // Knowledge sharing and looking at the future event September 20-21, 2004 Amsterdam, The Netherlands - Amsterdam: 2004. - P. 28-33. 
2. Ilinykh M. S., Maslov S. G. Constructive Electronic Publishing Based on Notion System and Interactive Dynamic Images//Knowledge-Based Media Analysis for Self-Adaptive and Agile Multi-Media, Proc. of the European Workshop for the Integration of Knwoledge, Semantics and Digital Media Technology, EWIMT 2004, November 25-26, 2004. - London, UK.

3. Ильиных М. С. Создание электронных изданий на основе системных представлений для поддержки профессиональной деятельности: дис. ... канд. техн. наук / ГОУ ВПО ИжГТУ. - Ижевск, 2005. $172 \mathrm{c}$.

4. Maslov S. G., Ilinykh M.S. Constructive Electronic Publication // Proc. of the $7^{\text {th }}$ International Workshop on Computer Science and Information Thecnologies CSIT2́005. - Ufa, 2005 - P. 190-194.

5. Маслов С. Г., Дунаев Д. А., Ильиных М. С. Среда конструктивной деятельности // Технологии информатизации профессиональной деятельности: Сб. труд. конф. Ижевск: НИЦ «Регулярная и хаотическая динамика», 2005. - C. 155-195.

6. Maslov S. G. The problems of constructive reading creation //Proc. of the $9^{\text {th }}$ International Workshop on Computer Science and Information Thecnologies CSIT2́007, Ufa-Krasnousolsk, Russia - Ufa.: USATU Publishers, 2007. - P. 16-20.

7. Маслов С. Г. Степени свободы в построении систем знаний // Всер. конф. «Знания - Онтологии Теории» с междунар. уч. 14-16 сентября 2007 г. Новосибирск - Новосибирск: Изд-во НГУ, 2007. C. $32-36$.

8. Бельтюков А. П., Маслов С. Г., Морозов О. А. Либернетическая парадигма в IT-сфере //Технологии информатизации профессиональной деятельности (в науке, образовании и промышленности): Сб. тр. II Всер. науч. конф. с междунар. уч. Часть І. Ижевск: ООО Информационно-издательский центр «Бон Анца», 2008. - С. 37-52.

9. Маслов С. Г. О формировании и распространении системы профессиональных знаний (либернетический подход) //Интеллектуальные системы: Тр. Восьмого межд. симпозиума. - М.: РУСАКИ, 2008. - С. 224-228.

10. Бельтюков А. П., Маслов С. Г., Морозов О. А. Конструктивные механизмы в IТ-сфере // Вестник Удмуртского университета. Сер. Математика. Механика. Компьютерные науки. - 2009. - Вып. 2. C. $102-109$.

11. Бельтюков А.П., Маслов С. Г. О терминологической системе для междисциплинарных исследований // Теория активных систем: тр. междунар. науч.-практ. конф. «Управление большими системами - 2009», 17-19 нояб. 2009 г., М., Россия / под общ. ред.: В. Н. Буркова, Д. А. Новикова. - М.: ИПУ РАН, 2009. - С. 232-235.

12. Редько В.Г. Модели адаптивного поведения - биологически инспирированный подход к искусственному интеллекту // Искусственный интеллект и принятие решений. - 2008. - 2. - С. 11-23. http://www.aidt.ru/

13. Шилин А. Самоучитель: как научиться быстро читать. - Мн.: Харвест, М.: АСТ, 2001. - 272 с.

14. Шелли П. Р. Фоточтение. http://nkozlov.ru/library/samorazvit/d3799/

15. Михайлов С. Скорочтение - шаманство над книгой. - СПб.: Питер, 2003. - 160 с.

16. Смородинская М.Д., Маркова Ю.П. О культуре чтения: что нужно знать каждому. - М.: Книга, 1984. - 88 c.

17. Леонтьева Н.Н. Автоматическое понимание текстов: системы, модели, ресурсы: учеб. пособие для студ. лингв. фак. вуз. - М.: Издательский цент «Академия», 2006. - 304 с.

18. Вольфенгаген В.Э. Аппликативные вычислительные технологии. Готовые решения. - М.: ЮрИнфоР - 2009. - 64 с. 


\section{A. P. Beltúkov, S. G. Maslov}

About problems of readers and the process of reading in the electronic environment

Situations of subject interaction with a system of knowledge, presented in the form of digital books are considered on the basis of system analysis. Com-parison of traditional forms of books is performed. Kinds of reading are clas-sified. Basic directions of development of digital books and technologies of reading in context of evolutionary knowledge system are offered.

Keywords: digital publications, constructive electronic publications, live book, fund of publications, the types of readers, the reading process, the types of reading, system analysis.

Mathematical Subject Classifications: 76G25

Бельтюков Анатолий Петрович, д. ф.-м. н., профессор, кафедра теоретических основ информатики, Удмуртский государственный университет 426034, Россия, г. Ижевск, ул. Университетская, 1, E-mail: belt@uni.udm.ru

Маслов Сергей Геннадьевич,к. т. н., кафедра теоретических основ информатики, Удмуртский государственный университет 426034, Россия, г. Ижевск, ул. Университетская, 1, E-mail: msh.sci.it@gmail.com 